\title{
Do trabalho ao reconhecimento: Axel Honneth entre Marx e Habermas
}

\author{
From work to recognition: Axel Honneth between Marx and Habermas
}

\author{
Nathalie Bressiani \\ nathalie.bressiani@ufabc.edu.br \\ (Universidade Federal do ABC, São Paulo, Brasil)
}

\begin{abstract}
Resumo: Em suas primeiras publicações, Axel Honneth realiza um frutífero confronto com Marx e Habermas e explicita, a partir deles, as tarefas que teriam ainda de ser enfrentadas por aqueles que procuram desenvolver uma teoria social crítica hoje. Tomando esse enfrentamento como central ao seu projeto crítico, analisarei aqui alguns textos de Honneth escritos na década de 1980 nos quais ele procura retomar o conceito de trabalho na teoria crítica e, ao tentar expandi-lo e complementá-lo, desenvolve um método de reconstrução negativa e se aproxima da categoria de reconhecimento. Com isso, meu objetivo é mostrar que a teoria honnethiana do reconhecimento pode ser compreendida como uma reformulação intersubjetiva de seu projeto inicial de desenvolver uma crítica imanente do capitalismo, que busca abarcar a dimensão moral das lutas de classe e identificar os potenciais de transformação inscritos nas experiências sociais de injustiça.
\end{abstract}

Palavras-chave: Honneth; Trabalho; Keywords: Honneth; Work; Recognition; Reconhecimento; Capitalismo; Marx; Habermas.

\begin{abstract}
In his first publications, Axel Honneth makes a fruitful confrontation with Marx and Habermas and explains the tasks that would still have to be faced by those who seek to develop a critical social theory today. Taking this confrontation as central to his critical project, I will analyze here some texts written by Honneth in the 1980's, in which he seeks to resume the concept of work in critical theory and, while trying to expand and to complement it, develops a method of negative reconstruction and approaches the recognition category. My aim is to show that Honneth's recognition theory can be understood as an intersubjective reformulation of his initial project of developing an immanent critique of capitalism able to encompass the moral dimension of class struggles and to identify a potential for transformation based on social experiences of injustice.
\end{abstract}

Capitalism; Marx; Habermas.

Para os leitores mais familiarizados com os textos em que Axel Honneth apresenta sua teoria do reconhecimento, pode parecer estranho que seus primeiros livros e artigos tenham sido dedicados a uma discussão sobre o legado e a atualidade da obra de Karl Marx (Honneth \& Joas 1980; Honneth \& Jaeggi 1980; Honneth 1980, 1981 e 1989a). Se observamos então as críticas dirigidas a ele por autores como Nancy Fraser, de acordo com a qual, ao dar centralidade ao conceito de reconhecimento, Honneth teria simplesmente desconsiderado questões e injustiças relacionadas à economia capitalista (Fraser 2001), suas incursões de juventude pelo marxismo 
podem parecer distantes e pouco importantes para os futuros desenvolvimentos de sua teoria. Isso, todavia, está longe de ser verdade. Os confrontos travados com Marx explicitam preocupações e objetivos que continuam a orientar o trabalho de Honneth e o levam a desenvolver, mais adiante, uma teoria crítica centrada na gramática moral da luta por reconhecimento. Jean-Philippe Deranty chega a afirmar, nessa direção, que a trajetória de Honneth seria melhor descrita como a de um marxista que se interessou pela teoria crítica, do que como a de um teórico crítico que se interessou pelo marxismo (Deranty 2009, p. 53).

É inegável, todavia, que o retorno de Honneth a Marx teve Jürgen Habermas, desde o início, como principal interlocutor. Os primeiros textos de Honneth se inserem diretamente no debate sobre o legado marxista despertado, no final da década de 1970, pela tentativa de Habermas de reconstruir o materialismo histórico a partir de um novo arcabouço teórico (Habermas 1976; Melo 2013a). Insatisfeito com a rejeição de Habermas do potencial transformador inscrito na atividade do trabalho e também com sua guinada em direção à pragmática universal, Honneth retoma Marx (e outros autores) na tentativa de reabilitar uma crítica imanente do trabalho e de resgatar uma base imanente para a crítica do capitalismo. Já nesse momento, entretanto, Honneth reconhece o avanço trazido pela guinada intersubjetiva de Habermas na teoria crítica e combina o resgate do potencial normativo do trabalho com uma reformulação do potencial emancipatório identificado por Habermas nas relações intersubjetivas. ${ }^{1}$

Neste artigo, meu objetivo é reconstruir esse duplo confronto e mostrar sua importância para a formulação da teoria do reconhecimento que viria a ser apresentada por Honneth na década de 1990. Com esse objetivo no horizonte, retomarei, nas duas primeiras seções do texto, os confrontos de Honneth com Marx e com Habermas. Na terceira seção, por sua vez, mostro como a categoria do reconhecimento começa a surgir nos textos de Honneth como uma resposta a questões e desafios que emergem desse projeto original. Mobilizarei, para isso, sobretudo os textos reunidos por Honneth na versão americana do livro Fragmentado Mundo do Social (1995), que inclui artigos e capítulos publicados ao longo da década de 1980; textos que refazem, dentre outros, seu percurso do trabalho ao reconhecimento. ${ }^{2}$

$1 \mathrm{Na}$ introdução de Fragmented world of the social, livro que reúne artigos desse período, Honneth afirma que, "a direção pela qual Habermas seguiu sua ideia original, empregando a pragmática universal como o meio teórico para analisar as pressuposições normativas da interação social, não conseguiu me convencer, desde o início, por razões inicialmente obscuras e um tanto difusas. [...] Precisamente porque essa reserva foi, no início, apenas uma reserva vagamente sentida, os ensaios a seguir documentam uma busca pela possibilidade de uma formulação alternativa da ideia original de Habermas" (Honneth 1995c, p. viii).

2 Embora a versão americana do livro tenha o mesmo título que o livro publicado por Honneth em 1990 em alemão, Die zerrissene Welt des Sozialen, há diferenças significativas entre eles. 0 livro em alemão possui doze capítulos, dos quais quatro não são incluídos em Fragmented World of the social - um capítulo sobre Walter Benjamin, um sobre Elias Canetti, um sobre Charles Taylor e outro sobre Avishai Margalit. Além dos outros oito capítulos que fazem parte da versão alemã do livro, a versão americana inclui mais oito capítulos que foram originalmente publicados em revistas ou em coletâneas de livros esparsas, além de uma introdução do autor para essa edição. Estes 


\section{Honneth e o marxismo: reformulando um conceito crítico de trabalho}

Para compreender o projeto de Axel Honneth, é importante notar que, desde seus primeiros escritos, ele rejeita que a crítica da sociedade possa ser realizada a partir de um ponto de vista externo à realidade social. Vinculando-se à teoria crítica, ele defende que a crítica social tem de ser imanente, isto é, depende da identificação de uma tendência estrutural à emancipação na própria sociedade criticada. Para ele, somente ao tomar essa tendência como ponto de partida, uma teoria se tornaria efetivamente consciente de suas origens pré-teóricas e poderia desenvolver uma crítica social embasada (Honneth 1995, pp. xii-xiv). Esse é o quadro teórico no qual se insere a tentativa do jovem Honneth de resgatar o projeto marxista de desenvolver uma crítica imanente da economia capitalista e dos processos alienantes em curso no mundo do trabalho.

Publicado originalmente em 1980, em um contexto no qual o diagnóstico predominante era o de que a tendência de crise do capitalismo havia sido neutralizada e o de que os potenciais de conflito teriam migrado para outras dimensões da vida social, "Trabalho e Ação Instrumental" é um dos primeiros artigos em que Honneth avança nessa direção (Honneth 1980). Já nesse texto, entretanto, ele admite que seu projeto esbarra em dificuldades significativas. Dentre elas, identificar um potencial crítico e transformador no âmbito do trabalho, mesmo no contexto do capitalismo tardio. De acordo com ele, não é trivial que, diante dessa tarefa, parte dos teóricos tenha rejeitado o potencial crítico do trabalho e, enveredando em outra direção, tenha passado a compreender o marxismo como uma teoria datada, que faria parte do ultrapassado edifício teórico do século XIX (Honneth 1981, p. 86, [1995, p. 3]). Também não é trivial, afirma, que a maior parte daqueles que continuaram a defender o projeto marxista tenha passado a reforçar suas tendências objetivistas e, com isso, subestimado as dificuldades enredadas na tarefa de vincular a crítica da economia política e a análise do capital com uma teoria da emancipação orientada à prática (idem, pp. 88-90 [pp. 4-5]).

Embora reconheça as dificuldades suscitadas por seu projeto, Honneth se contrapõe a essas duas tendências. No que se refere à primeira, rejeita a neutralização normativa do trabalho e defende que a ampliação de formas alienadas de trabalho não impede sua crítica, ao contrário, torna-a mais urgente. No que se refere à segunda, insiste na importância da dimensão normativa da crítica e rejeita que ela possa ser realizada a partir de um modelo sistêmico de crise que explica a transformação social a partir de um modelo funcionalista - não apenas porque a passagem entre esses dois níveis se mostrou problemática, mas também porque, ao menos naquele momento, a tendência de crise sistêmica do capitalismo parecia refutada pela realidade do

textos são centrais para a compreensão da trajetória de Honneth até a elaboração da teoria do reconhecimento e são sobretudo eles que serão aqui analisados, particularmente aqueles em que Honneth estabelece um confronto mais direto com Marx e com Habermas (Honneth 1980, 1981, 1982, 1989a, 1995). 
capitalismo tardio. Para Honneth, todavia, desse diagnóstico não se segue que Marx tenha se tornado obsoleto. Pelo contrário. Por mover-se o interior do quadro de uma crítica imanente da sociedade, Marx ainda forneceria as melhores ferramentas conceituais para a elaboração de uma nova crítica do capitalismo. Consciente da necessidade de estabelecer um vínculo sistemático entre transformação social e análise da sociedade, Marx desenvolve um conceito de trabalho social que pode ser alçado à categoria central de uma teoria crítica do capitalismo (Honneth 1981, parte II; Honneth 1980, parte I).

Segundo Honneth, ao compreender o trabalho social como atividade responsável pelos processos de apropriação coletiva da natureza, Marx explicita seu papel nos processos de reprodução social. 0 trabalho social corresponde, nesse caso, à atividade propriamente humana por meio da qual produzimos e reproduzimos materialmente o mundo em que vivemos. Partindo dessa tese, de caráter teórico-social, Marx pode defender que a compreensão do funcionamento das sociedades e de seus processos históricos de transformação requer, em primeiro lugar, uma análise da estrutura técnica e da forma de organização social do trabalho (Honneth 1980, pp. 186-7 [1995, p. 186]). Marx, porém, não compreende o trabalho apenas como a atividade por meio da qual os seres humanos se apropriam e transformam a natureza para garantir a reprodução material da sociedade. Como afirma Honneth, o trabalho, para ele, seria "sempre mais do que a mera utilização produtiva de energia" e desempenha também uma importante função no nível da teoria do conhecimento e no nível da teoria prático-moral (Honneth 1981, p. 96, [1995, p. 9]). A atividade produtiva seria central no processo pelo qual adquirimos acesso à realidade e no processo de aprendizagem por meio do qual "as pessoas percebem que suas capacidades e necessidades extrapolam as possibilidades dadas no presente" (Honneth 1980, p. 188 [1995, p.17]). ${ }^{3}$ Em Marx, portanto, o trabalho possuiria ao menos três dimensões.

Embora o conceito marxista de trabalho tenha sido alvo de diversos questionamentos, Honneth defende que é ele que torna sua teoria plena de consequências para os dias de hoje. Isso decorre, sobretudo, de sua dimensão prático-moral, que permite a Marx enxergar o trabalho como uma atividade que contém um potencial normativo de transformação social. Não é à toa que o artigo de Honneth enfatize essa dimensão. De acordo com ele, seguindo Hegel, Marx compreende o trabalho social como uma atividade em que o trabalhador objetiva suas habilidades e capacidades cognitivas no objeto produzido e, reconhecendo-as nele, adquire retrospectivamente autoconsciência de si mesmo enquanto sujeito. Extrapolando esse quadro para o campo do autodesenvolvimento da espécie, com a ajuda do materialismo antropológico de Feuerbach, Marx teria conseguido enxergar o trabalho como um processo por meio do qual os seres humanos, enquanto espécie, objetivam suas capacidades e necessidades e, reconhecendo-as, dão início a um

3 A tradução para o português das fontes em língua estrangeira foi feita por mim, a não ser quando expressamente indicado. 
processo consciente de aprendizagem que pode levá-los, inclusive, a questionar e transformar a forma atual de organização social do trabalho. Vale dizer, sua forma capitalista de organização, que os impede de desenvolver plenamente suas capacidades e satisfazer plenamente suas necessidades. Segundo Honneth, é com base nesse modelo que Marx realiza uma crítica imanente da economia capitalista, ao menos antes de enveredar para uma análise funcionalista do capital. Como afirma Honneth, "com a ajuda de um modelo antropologicamente radicalizado de trabalho como um processo de externalização, Marx interpreta a época histórica do capitalismo como uma formação socioeconômica que faz com que seja estruturalmente difícil ou impossível para o sujeito trabalhador se identificar em seus próprios produtos" (idem, p. 189, [1995, p. 19]).

Honneth ressalta a importância dessa dimensão antropológico-normativa do trabalho para a crítica marxista. Apesar disso, ele sustenta que Marx não diferencia suficientemente a atividade do trabalho de outras atividades, como a própria práxis revolucionária, nem elucida como a categoria de trabalho social poderia ser aplicada para explicar um processo prático de transformação social. Esses problemas, afirma, decorrem da ausência, em Marx, de uma explicação mais detida sobre como se daria o processo prático-moral de aprendizagem em um contexto no qual o trabalho social estaria desprovido de seu potencial formativo. Isso, ao menos nas duas teorias da revolução que são apresentadas nos textos em que Marx se move no quadro de uma teoria da ação.

$\mathrm{Na}$ primeira delas, apresentada nos Manuscritos de Paris, Marx teria desenvolvido uma tese de caráter mais antropológico, de acordo com a qual o trabalho corresponde a um processo de objetivação que permite que os sujeitos enxerguem a si mesmos nos produtos de seu trabalho e tomem consciência de si enquanto sujeitos individuais e coletivos capazes de ação histórica. Com base nisso, afirma Honneth, Marx compreende o próprio processo de desenvolvimento histórico como uma sucessão de etapas de objetivação, que caminham em direção à efetivação plena das capacidades e necessidades humanas. 0 capitalismo e a propriedade privada surgem, nesse quadro, como obstáculos. Com eles, o trabalho se torna alienado, isto é, passa a ser orientado ao lucro e não à "continuação do processo histórico de objetivação de todos 'os poderes essenciais' da humanidade” (Honneth 1980, p. 191, [1995, p. 21]). O trabalho alienado corresponde, assim, a um bloqueio ao desdobramento das capacidades humanas na realidade social, motivo pelo qual é criticado por Marx em nome da emancipação humana.

Embora reconheça a complexidade do modelo crítico desenvolvido por Marx nesse período, Honneth afirma que ele não elucida um passo central para sua argumentação, a saber, como “a emancipação dos trabalhadores poderia ser explicada com base nas relações imanentes do trabalho alienado" (idem, ibidem). ${ }^{4}$

\footnotetext{
4 Segundo Honneth, Marx segue aqui o argumento de Hegel de acordo com o qual haveria um excedente normativo mesmo no trabalho alienado, que apontaria para além dele. Marx, porém, não teria desenvolvido esse ponto e não pode mobilizar o modelo hegeliano da dialética entre senhor e
} 
Ele continua atribuindo um excedente normativo à atividade do trabalho, mas não elucida como trabalhadores formados no contexto do trabalho alienado e desprovidos das condições necessárias à formação de autoconsciência poderiam desenvolver uma orientação prática emancipatória (cf. Melo 2013b). Mesmo possuindo um critério normativo, com base no qual pode criticar as relações alienadas de trabalho, Marx não teria explicado as raízes do interesse emancipatório que poderia motivar lutas por transformação social, nem descrito em que consistiria essa práxis revolucionária. ${ }^{5}$

Em seus textos econômicos, Marx desloca parte desse problema ao transformar a distinção entre trabalho alienado e não alienado em uma contraposição entre duas formas de organização do trabalho na história empírica: o trabalho artesanal e o trabalho industrial. Na leitura de Honneth, a concepção do trabalho enquanto objetivação é mantida, mas agora a partir de uma imagem do trabalho artesanal como uma atividade autorregulada na qual o artesão possui uma intimidade familiar com seu objeto. Sobretudo nos Grundrisse, o trabalho social remeteria ao "conceito de um processo produtivo orientado pelo próprio conhecimento do sujeito trabalhador, que demanda a totalidade das capacidades humanas para a ação" (idem, p. 192-3, [p. 22]). 0 trabalho alienado, em contrapartida, passa a ser pensado na forma do trabalho abstrato, que se torna predominante com a industrialização e corresponde a uma atividade fragmentada e desvinculada do conhecimento do trabalhador. Para Honneth, todavia, esse deslocamento conceitual não oferece uma resposta aos problemas suscitados pelo modelo anterior. Afinal, Marx permanece sem explicar como se daria a passagem da forma abstrata de trabalho para sua forma autônoma. Para isso, sustenta Honneth, ele precisaria ter mostrado como, mesmo no contexto capitalista de produção industrial, os trabalhadores poderiam antecipar contrafaticamente uma forma autônoma de trabalho que incorporasse o conhecimento dos trabalhadores. Em outras palavras, Marx precisaria ter mostrado como, mesmo no contexto de produção capitalista, ainda haveria uma base comunicativa que manteria a forma artesanal de trabalho no horizonte dos trabalhadores e pressionaria em direção à sua realização (idem, pp. 194-5, [pp. 23-4]).

Nos momentos em que enfrenta essa questão, porém, a estratégia de Marx é outra. Sobretudo em seus escritos de maturidade, ele caminha em direção a uma análise funcionalista do capital e passa a explicitar como o próprio desenvolvimento do capitalismo contribui para a organização e para o disciplinamento do proletariado,

escravo, em que o último busca estabelecer uma relação de reconhecimento intersubjetivo com o primeiro, para explicar esse excedente. Marx tem de explicar como uma consciência emancipatória pode surgir mesmo em uma situação de trabalho alienado. Como mostra Thomas Meyer, citado por Honneth, "Marx busca, na realização do princípio do proletariado, não uma mediação com a consciência do senhor, mas sua substituição pela consciência do escravo" (Meyer apud Honneth 1980, p. 191 [1995, p. 21]).

5 Nesse momento, Honneth parece unir dois problemas: como pensar a formação de um interesse emancipatório e no que consiste a práxis emancipatória. Em sua teoria do reconhecimento, entretanto, ele os distingue: procura analisar como surge a consciência da injustiça e como ela pode desencadear em lutas políticas por reconhecimento e, portanto, por transformações sociais (Honneth 1992, caps. 6 e 8). 
mostrando que "o processo de organização capitalista do trabalho iria socializar a classe trabalhadora em um sujeito coletivo disciplinado, organizado e tecnicamente qualificado" (idem, pp. 196-7 [p. 25]). A concentração cada vez maior do capital em poucas mãos aproximaria e uniria os trabalhadores; a exigência de qualificação permitiria a eles a formação da autodisciplina e da capacidade de cooperação; por fim, a exigência de educação aumentaria o acesso do proletariado às reservas do conhecimento social. Nos três casos, a lógica interna de desenvolvimento do capitalismo geraria as condições sociais necessárias à sua superação prática. Para Honneth, embora sejam uma tentativa de resolver a passagem para a práxis, esses diferentes processos não explicam o potencial prático-moral de aprendizagem do trabalho social. Sua ênfase recai, antes, em como o desenvolvimento do capitalismo contribui para o processo de disciplinamento e qualificação técnica da classe trabalhadora. Com esse passo, mostra-se que o trabalho oferece meios técnicos para a libertação, mas o desejo por ela permanece inteiramente inexplicado. Marx teria pressuposto novamente uma consciência prático-normativa prévia no trabalhador, sem explicar como ela teria se formado e de onde teria se originado. Como afirma Honneth, "tanto no modelo argumentativo [funcionalista], como em seus primeiros escritos, permanece obscuro de que modo o processo de formação dessa consciência emancipatória estaria ancorado nas estruturas de ação do trabalho social” (idem, ibidem). Apesar de tentar atribuir à categoria de trabalho social as várias funções necessárias ao estabelecimento da relação entre a crítica do capitalismo e a sua superação prática, Marx não teria sido inteiramente bem-sucedido nessa empreitada.

Para Honneth, os desenvolvimentos que tiveram lugar na esfera da produção capitalista desde então contribuíram ainda mais para colocar em questão o potencial transformador atribuído por Marx ao trabalho. Com a transição para o capitalismo industrial, ainda em curso no período histórico vivido por Marx, o conhecimento e a organização necessários ao trabalho são inteiramente centralizados, o trabalho é fragmentado e reduzido a seus elementos mais básicos e o processo de produção é completamente desvinculado do conhecimento e das habilidades dos trabalhadores, passando a ser ditado pelo ritmo forçado e mecânico das máquinas (cf. Braverman 1978 apud Honneth 1980, p. 200 [1995, p. 27]). A experiência simultânea das formas artesanal e industrial do trabalho, que ainda teria sido a de Marx, é solapada pela absolutização da sua forma industrial e o trabalho parece se tornar uma atividade destituída de qualquer potencial de aprendizagem moral.

Essas transformações no âmbito do trabalho possuem, segundo Honneth, um impacto tão profundo que podem ser observadas até mesmo nos modos de conceber o trabalho na sociologia e na filosofia social. Na sociologia, o trabalho começa a ser analisado cada vez mais apenas da perspectiva da racionalização produtiva, o que faz com que o cerne das preocupações passe à forma de organização da produção e com que as dimensões culturais, normativas e psicológicas do trabalho entrem em cena apenas em discussões sobre os entraves a esse processo de racionalização. No 
campo da filosofia social, temos um movimento semelhante, explicitado por Honneth a partir de Max Scheler e Hannah Arendt: enquanto, em Scheler, o trabalho é visto como um fardo, um sofrimento que somos obrigados a enfrentar para sobreviver, Arendt o concebe como uma atividade ditada pela natureza cujo sentido e valor são conferidos de fora. ${ }^{6}$ Em todas essas análises, o trabalho perde a dimensão práticomoral que the havia sido conferida por Hegel e Marx. ${ }^{7}$ Como afirma Honneth sobre esse processo:

Sob a pressão exercida pela experiência da rápida mecanização do trabalho industrial, filósofos sociais e cientistas sociais, desde a virada do século, passaram a enfatizar excessivamente os aspectos técnicos e economicamente funcionais do conceito de trabalho, extirpando dele todo o significado emancipatório que Marx e Hegel reivindicavam para ele (idem, p. 201 [p. 28]).

Ainda que reconheça as dificuldades colocadas pelos vários desenvolvimentos sociais e problemas conceituais discutidos acima, Honneth recusa que o marxismo e a categoria de trabalho social tenham deixado de ser relevantes. Se, por um lado, não faria mais sentido desenvolver uma teoria funcionalista da crise capitalista, nem partir dela para explicar os potenciais de transformação (que só teria como ser pensada do ponto de vista da teoria da ação), disso não decorreria a necessidade de abandonar o projeto marxista de elaborar uma crítica da sociedade capitalista a partir da categoria do trabalho social. A suposta ausência de significado do trabalho decorre, segundo Honneth, da situação atual de alienação das relações de produção. Ela não é estrutural, mas conjectural, e tem de ser criticada. Por esse motivo, ele se contrapõe a autores que, inseridos nesse novo contexto, esvaziaram o trabalho de qualquer significado prático-moral. Eles teriam deixado de lado a importante tarefa de criticar as formas alienadas de trabalho, assumindo-as como normais. Opondose então principalmente a Habermas, que entende o trabalho nos termos de uma ação meramente instrumental, Honneth procura reconstruir os contornos de uma categoria crítica de trabalho social.

6 Em A condição humana, Arendt diferencia trabalho, obra e ação. Enquanto o primeiro diz respeito às atividades dirigidas, de forma imediata, à satisfação das necessidades da vida, a segunda engloba o mundo que os seres humanos criam por meio do trabalho. Nos dois casos, as atividades são ditadas pela natureza e têm seu valor dado pelos produtos que geram. A ação, por sua vez, tem valor em si mesma e diz respeito às relações intersubjetivas por meio das quais as pessoas criam autonomamente um mundo. Apenas nesse último caso, como defende Arendt em Entre o passado e o futuro, temos uma ação livre e com uma dimensão propriamente humana e normativa (Arendt 2007; 2005).

7 A situação na teoria crítica, apesar de diversa, não seria inteiramente distinta. Para Honneth, as tentativas de Lukács e Marcuse de resgatar uma crítica do trabalho no contexto do trabalho industrial não recaem em uma teoria funcionalista, mas lançam mão de uma noção problemática de macrossujeito para unir todos os processos fragmentados de trabalho. Por outro lado, autores como Adorno e Horkheimer, que se recusam a abandonar o paradigma do trabalho, atribuem a ele um caráter meramente instrumental, cujo desdobramento é a dominação na natureza e do próprio ser humano. Como resultado, a dimensão emancipatória do trabalho é inteiramente recusada ou retomada de forma problemática por aqueles que a defendem (Honneth 1980, pp. 211-15 [1995, pp. 35-39]). 
Habermas desenvolve um conceito de trabalho a partir da antropologia filosófica de Arnold Gehlen, para quem a constituição orgânica incompleta dos seres humanos, que nascem desamparados, os impele em direção a um processo de aprendizagem técnico-instrumental. Para Gehlen (2016), ainda que a subespecialização humana possa inicialmente parecer uma desvantagem, ela logo se mostra vantajosa e permite que, ao contrário dos demais animais, os seres humanos sejam capazes de ação social e não tenham de se restringir à eterna repetição de respostas instintivas de comportamento (Deranty 2009, p. 163). O processo de aprendizagem técnicoinstrumental pelo qual a espécie humana tenta compensar sua baixa capacidade de adaptação permite que as pessoas consigam se adaptar à natureza e transformá-la por meio do trabalho (Honneth \& Joas 1980, p. 55). Tendo isso em vista, Habermas reconstrói a racionalidade instrumental a partir da atividade do trabalho, cuja lógica interna de desenvolvimento pressionaria em direção à ampliação da dominação técnico-instrumental da natureza (Honneth 1980, p. 220 [1995, p. 41]). Em Habermas, portanto, o trabalho mantém uma dimensão econômica e uma antropológica: ele permanece central aos processos de reprodução material e está ancorado antropologicamente. 0 que se perde, afirma Honneth, é a dimensão prático-moral: o trabalho deixa de ser visto como uma forma de objetivação que seria central ao processo de formação da autoconsciência.

Para Honneth, todavia, essa consequência não decorre diretamente da concepção do trabalho como ação instrumental. Ao concebê-lo desse modo, Habermas não impede o estabelecimento de uma distinção entre as ações instrumentais que são coordenadas pelos atores sociais de modo autônomo e aquelas ações instrumentais que são ditadas por forças sociais que os sujeitos não controlam. Habermas, porém, não estabelece essa distinção. Ele reconstrói a lógica interna de desenvolvimento do trabalho como um processo contínuo de racionalização da produção, que se desdobra como que pelas costas dos sujeitos sociais. Com esse passo, de acordo com Honneth, ele não apenas cede demais à teoria dos sistemas (Honneth 1989b), como perde a oportunidade de distinguir formas alienadas e não alienadas de ação instrumental, o que poderia servir de base para uma crítica imanente do capitalismo. Há, segundo Honneth, formas de trabalho que são autônomas, isto é, atos instrumentais regidos pelo trabalhador que se apropria efetivamente de sua atividade produtiva. Em contrapartida, há formas de trabalho não autônomas e alienadas, aquelas sobre as quais o trabalhador não possui qualquer controle e que não são estruturadas por seu conhecimento ou habilidades. Para Honneth, um conceito crítico de trabalho tem de dar conta dessas diferenças, que se faziam presentes em Marx, mas teriam se perdido. É exatamente esse caminho - aberto mas não trilhado por Habermas aquele que Honneth procura seguir nesse texto, ainda que de modo programático (Teixeira 2016).

Para que esse projeto seja realizado, é preciso enfrentar os problemas 
identificados no conceito marxista de trabalho social. É preciso mostrar que, mesmo em um contexto no qual o trabalho alienado se tornou predominante, continua havendo um impulso que pressiona em direção à sua superação, isto é, em direção à reapropriação do trabalho. Ora, se assumirmos que essa tarefa faz sentido, a pergunta que se impõe é, então: como identificar esse impulso em um contexto em que as lutas de classe parecem ter sido neutralizadas e a classe trabalhadora inteiramente integrada à realidade do capitalismo tardio? De acordo com Honneth, a resposta é: voltando nossa atenção à experiência social gerada pela destruição de formas autônomas de trabalho, bem como analisando as tentativas de reapropriação que decorrem dessas experiências. Caso sejam capazes de mostrar que as pessoas não reagem de modo indiferente à fragmentação e à alienação do trabalho, essas práticas e experiências indicarão que este permanece central nos processos de formação da identidade e que seu potencial crítico não foi neutralizado.

Dando um primeiro passo em direção à realização desse projeto, Honneth defende em "Trabalho e Ação Instrumental" que o teórico crítico deve voltar os olhos para os atos de trabalho que "reivindicam sua autonomia mesmo na realidade das formas de trabalho externamente determinadas" (Honneth 1980, p. 230 [1995, p. 47]). Embora não sejam facilmente observados, esses atos fazem parte da realidade social, como teria mostrado Phillipe Bernoux (1979), cujo trabalho explicita as constantes tentativas dos trabalhadores de subverter e modificar criativamente os processos de produção. Essas tentativas de reapropriação englobam desde estratégias para reorganizar o ritmo e os espaços de trabalho até iniciativas para desenvolver cooperativamente novas técnicas e tecnologias na fábrica. Segundo Honneth, tais tentativas apontam a importância do trabalho para as pessoas e seu interesse em estruturá-lo autonomamente: elas mostram que os trabalhadores não são indiferentes aos processos de alienação do trabalho. Mais do que isso, elas apontam a existência de práticas de oposição que podem gerar movimentos sociais por transformação. Se enxergamos isso, afirma Honneth, temos que o potencial de conflito no interior do âmbito do trabalho não está desativado, mas latente. Caberia ao teórico crítico identificá-lo e reconstruí-lo.

A correção marxista da teoria de Habermas passa, desse modo, pela reabilitação da crítica do trabalho, possibilitada pela distinção entre duas diferentes formas de ação instrumental. É com base nessa distinção que Honneth identifica as patologias no âmbito da produção, entendidas nesse momento como trabalho alienado. É, também, a partir dela que ele toma como emancipatórias as práticas de reapropriação por meio das quais os trabalhadores procuram superar essas deformações e retomar o controle de sua atividade laboral, ambas desconsideradas por Habermas. Reformulando elementos do projeto crítico de Marx, Honneth procura então resolver pontos cegos da teoria de Habermas e de todos aqueles que, como ele, não se deram conta da importância do trabalho para a autorrealização e para o 
processo de formação da identidade dos indivíduos. Ao mesmo tempo em que corrige Habermas, porém, Honneth admite que este já o teria convencido de que a crítica requer também uma dimensão intersubjetiva e não pode ignorar a dinâmica moral da interação social. Isso significa que o projeto de Marx não sai ileso do enfrentamento promovido por Honneth entre ele e Habermas. Atento aos erros e acertos de ambos, Honneth parece utilizar Marx para corrigir Habermas e Habermas para corrigir Marx. ${ }^{8}$

\section{Honneth e Habermas: da importância da experiência moral}

O surgimento da teoria crítica foi profundamente marcado pela experiência de perda da confiança no proletariado e da ascensão do fascismo, do nazismo e do stalinismo (Honneth 1981, pp. 183-4 [1995, p. 206]). Já nos anos 1930, as pesquisas interdisciplinares realizadas sob a direção de Horkheimer no Instituto de Pesquisa Social são orientadas à compreensão dos mecanismos sociais responsáveis pela integração da classe proletária à sociedade capitalista e pela neutralização dos conflitos de classe. Ao longo das décadas subsequentes, afirma Honneth, esse diagnóstico de neutralização das lutas de classe adquire contornos ainda mais pessimistas, dando lugar à imagem de uma sociedade totalmente integrada, na qual os potenciais de transformação estariam estruturalmente bloqueados. Sobretudo no trabalho de membros do círculo interno da teoria crítica, como Adorno, Horkheimer e Marcuse, essa imagem é ainda acompanhada por uma filosofia da história que enxerga o desenvolvimento social nos termos do desenvolvimento das forças produtivas, que levaria a uma ampliação contínua da reificação (Honneth 1987).

Desde seu surgimento, portanto, a teoria crítica se vê confrontada com o importante desafio de reestabelecer as bases imanentes da crítica social. Mesmo aqueles que defendem a existência de um potencial de emancipatório inscrito na atividade do trabalho, como Honneth, não podem se furtar à tarefa de explicitá-lo. Cabe a eles mostrar como, mesmo no contexto capitalista de produção industrial, os trabalhadores poderiam antecipar uma forma autônoma de trabalho que pressiona em direção à sua realização. Caberia a eles mostrar que a fragmentação e a alienação do trabalho não são experienciadas de modo neutro pelos sujeitos sociais, indicando que tais fenômenos contêm em si, mesmo que de modo latente, um potencial de transformação. Consciente dessas tarefas, Honneth dedica a elas diversos textos, nos quais começa a esboçar uma estratégia para realizá-las.

Honneth, entretanto, não para por aqui e analisa também o trabalho daqueles que não mais identificam uma dimensão emancipatória no âmbito da produção e se veem diante da tarefa de repensar as bases da crítica social como um todo. É nesse

8 Inverto, com isso, a afirmação de Deranty de que "Honneth usa Habermas para corrigir Marx e Marx para corrigir Habermas" (Deranty 2009, p. 11). 
contexto que podemos compreender os textos nos quais reconstrói o modelo crítico de Adorno e Habermas, autores que oferecem respostas distintas a esse mesmo problema. 0 projeto adorniano de desenvolver uma crítica social a partir de uma reflexão não coercitiva sobre um material metodologicamente não estruturado é interpretado por Honneth, nesse quadro, como uma tentativa de resgatar uma experiência estética que se opõe à lógica abstrata da troca de mercadorias. 0 resultado é uma teoria crítica, mas uma destituída de suas intenções práticas originais (Honneth 1982, p. 113). Habermas ofereceria uma resposta distinta e mais promissora ao desafio.

Como vimos acima, Habermas defende que a forma instrumental de racionalidade e as regras de abstração por meio das quais apreendemos os objetos podem ser diretamente reconstruídas a partir da atividade do trabalho, cuja lógica interna de desenvolvimento pressionaria em direção à ampliação continua da capacidade de produção e de sua eficiência. Embora compreenda o trabalho nesses termos, Habermas nega que o desenvolvimento histórico corresponda a um processo de desdobramento da racionalidade instrumental que levaria a uma dominação social cada vez maior. Isso porque, ao lado do trabalho, entendido como o responsável pela reprodução material da sociedade, ele analisa uma segunda forma de ação, a comunicativa, na qual estariam ancorados os processos prático-morais de aprendizagem. Reconstruindo, então, a racionalidade inerente à ação comunicativa, Habermas explicita uma segunda dinâmica do desenvolvimento social, que estaria atrelada aos processos simbólicos de reprodução da sociedade. Seu objetivo, com isso, é mostrar que a racionalidade comunicativa inscrita na interação social - que se diferencia da racionalidade instrumental inscrita no trabalho - pressiona em direção à realização de uma comunicação livre de impedimentos, da qual depende o estabelecimento do entendimento recíproco. Habermas diferencia, desse modo, duas dinâmicas de desenvolvimento social e assevera a existência de um domínio intersubjetivo de ação, no interior do qual identifica os potenciais emancipatórios que não mais encontrava nas estruturas da atividade laboral.

Mesmo que discorde da noção funcionalista de trabalho e do diagnóstico da neutralização dos conflitos de classe, Honneth reconhece o alcance da distinção habermasiana entre trabalho e interação. Com ela, Habermas teria chamado atenção para uma importante dimensão da ação social e permitido uma melhor compreensão das diferentes formas de reprodução social, concebida de modo unilateral por Marx e pelos teóricos críticos que o antecederam. ${ }^{9}$ Para Honneth, portanto, o projeto de resgatar um conceito crítico de trabalho não implica a rejeição da importância da interação: uma teoria crítica das sociedades contemporâneas exigiria, pelo contrário, que as dimensões normativas dessas duas formas de ação fossem conciliadas. Segundo

9 Como afirma Honneth, "hoje, uma teoria social crítica inspirada em Marx só tem como recobrar seu potencial crítico se a priorização funcional da esfera econômica for deixada de lado e a importância dos outros domínios de ação forem considerados" (1989a, p. 90a, p. 5i) 
ele, “o progresso representado pela 'virada intersubjetiva' na teoria social crítica foi pago com o desaparecimento do potencial de conflito ainda disponível no trabalho social” (Honneth 1980, p. 214, [1995, p. 40]), mas isso não significa que o potencial normativo da interação $e$ o do trabalho não podem ser articulados numa mesma teoria. Convencido da importância da interação social e do trabalho para teoria crítica, Honneth procura então reconstruir a normatividade das duas atividades. Como diz Eleonora Piromalli a esse respeito:

embora aceite a diferenciação habermasiana entre ação comunicativa e instrumental, Honneth a reformula em um sentido mais normativo: as duas esferas, a da comunicação e a da atividade laboral, são transformadas em esferas caracterizadas por uma normatividade interna, uma a partir do ponto de vista do entendimento discursivo, como em Habermas, a outra a partir da perspectiva da "apropriação". A ação técnicoinstrumental propriamente dita, desprovida de conotações normativas, é tirada do quadro da teoria: esta, da forma em que é proposta por Honneth, chama atenção apenas para a estrutura moral da sociedade (Piromalli 2012a, p. 30).

Honneth aceita, assim, a crítica de Habermas ao monismo marxista, ao mesmo tempo em que rejeita os termos de seu dualismo. Ao fazer isso, contudo, seu alvo não é apenas a compreensão de Habermas sobre o trabalho como ação instrumental, mas também seu modo de reconstruir a normatividade da interação social.

Honneth, como vimos, rejeita o diagnóstico de que o capitalismo tardio estaria marcado pela neutralização dos potenciais de conflito no âmbito do trabalho. Para ele, o fato de que lutas de classe não eclodiram não quer dizer que os trabalhadores tenham sido integrados ao sistema capitalista. Não é porque as pessoas continuam desempenhando pragmaticamente suas atividades produtivas e mantêm os processos de reprodução material em marcha que elas consideram esses processos legítimos. Ainda que os programas de compensação social e a regulação do trabalho tenham, na segunda metade do século XX e nos países do centro do capitalismo, satisfeito interesses materiais e garantido tempo livre, eles não são capazes de satisfazer as expectativas dos trabalhadores sobre suas próprias atividades de trabalho, algo que ficaria claro se olhássemos para as práticas de resistência nas fábricas. Para Honneth, por não tomar as experiências de injustiça como ponto de partida, Habermas perde de vista essas práticas de resistência e enxerga apenas aqueles movimentos sociais mais articulados, que já adquiriram algum espaço na esfera pública. Movimentos que, não por acaso, costumam ser compostos por grupos privilegiados, que não enfrentam os mesmos obstáculos que os demais para terem voz na esfera pública oficial e possuem maior facilidade para articular suas demandas em termos universalistas. ${ }^{10}$

10 Nestas críticas a Habermas, Honneth parece partir de diagnósticos apresentados em livros como Técnica e ciência como ideologia, de 1968, onde Habermas vê na revolta estudantil o maior potencial de contestação (exatamente porque estes não têm como ser facilmente integrados ao sistema capitalista), e Problemas de Legitimação do Capitalismo Tardio, de 1973, no qual Habermas identifica potenciais de transformação nas crises de legitimação que podem advir da politização de novas questões, gerada pela entrada do planejamento estatal em áreas como a 
O modelo crítico de Habermas privilegiaria, assim, a expressão moral de uma elite intelectual que já teria aprendido a formular argumentativamente suas reivindicações e enfatizaria apenas aquelas reivindicações sociais já plenamente articuladas em termos universalistas, isto é, aquelas que se colocam no debate público como a expressão neutra de princípios sociais de justiça. Ele ignoraria, por conseguinte, o que Honneth denomina, a partir de Barrington Moore, de "consciência da injustiça", a saber, a moralidade social não escrita das classes dominadas que, apesar de "não conter ideais de uma ordem moral total ou projeções de uma sociedade justa abstraída de situações particulares”, possui “um sensor altamente sensível às violações de demandas morais intuitivamente reconhecidas" (Honneth 1981, p. 187 [1995, p. 209]). Seguindo Moore, Honneth defende então que há uma grande diferença entre as ideias básicas de justiça formuladas e defendidas pela vanguarda política e por especialistas da cultura burguesa, por um lado, e a moralidade social das classes dominadas, que possui um caráter fortemente fragmentado, por outro. Enquanto as classes mais altas conseguem articular suas demandas em um sistema coerente de valores e crenças, conferindo a ele uma aparência de universalidade e desconexão com experiências específicas, as classes mais baixas costumam fazer demandas menos sistemáticas, mais próximas das experiências negativas e específicas de injustiça que estão em sua origem. Para Honneth, mesmo que não sejam articuladas em uma concepção positiva de justiça, essas demandas expressam a consciência da injustiça das classes dominadas, que está ancorada em padrões morais complexos e possui potenciais de transformação social. Estes, porém, ainda não teriam sido sistematizados.

Identificar essas demandas e articular os padrões morais que lhes dão origem, contudo, não é uma tarefa simples. Ao contrário do que ocorre com os valores e ideais de justiça já articulados e publicizados no interior da esfera pública, que podem ser mais facilmente acessados pelo teórico, os critérios e padrões morais implícitos nas experiências negativas de injustiça estão "ocultos" e têm de ser devidamente reconstruídos para que se tornem acessíveis. Para poder detectar então os vários mecanismos de dominação, bem como as formas empiricamente efetivas de moralidade e os conflitos morais que não conseguem chegar à esfera pública hegemônica, Honneth substitui a reconstrução habermasiana da estrutura normativa da ação comunicativa pela reconstrução da experiência de injustiça. É com esse projeto no horizonte que ele escreve, em 1981, "Consciência moral e dominação de classe", artigo onde analisa o processo de formação da consciência de injustiça das classes dominadas. Seu objetivo é mostrar que "há um potencial de expectativas de justiça, demandas por necessidades e ideais de felicidade preservados negativamente na consciência de injustiça desses grupos sociais” (Honneth 1981, p. 191 [1995,

educação, a saúde etc. (Habermas 1973; 2011). 
p. 212]), potenciais cuja articulação e publicização são bloqueadas por diferentes mecanismos de dominação, mas que nem por isso foram neutralizados.

Para fazer isso, em um primeiro momento, Honneth questiona a consistência da teoria de Lawrence Kohlberg sobre o processo de desenvolvimento da consciência moral, que é retomada por Habermas (idem, p. 188 [p. 210]). Segundo Honneth, os sujeitos sociais estão sempre vinculados emocionalmente aos seus contextos e o desenvolvimento da consciência moral não pode ser pensado de forma unidimensional, como resultado de um processo contínuo ao longo do qual os sujeitos ampliam a capacidade de abstração e de universalização de seus juízos morais. Pensar o desenvolvimento moral nesses termos limitados, afirma Honneth, resulta na tendência de estigmatizar os grupos excluídos como menos capazes de juízo moral e desagua em uma concepção restrita de moralidade que deixa de lado os elementos contidos nas experiências morais de determinados sujeitos e grupos sociais. No que diz respeito ao primeiro ponto, Honneth procura mostrar que a dificuldade de sistematização por parte das classes trabalhadoras não decorre de um déficit cognitivo, mas das características de seu processo de formação: menor acesso aos meios simbólicos que permitem a tradução de suas experiências em sistemas de valor mais abstratos e, também, menor pressão para fazê-lo. Isso, todavia, não significa que as experiências morais desses grupos sejam inferiores ou façam parte de um estágio anterior de desenvolvimento moral. ${ }^{11}$ Pelo contrário, elas contêm potenciais morais que poderiam levar, inclusive, a uma ampliação de concepções existentes de moralidade. Esses potenciais, contudo, não têm como ser acessados diretamente pelo teórico, mas apenas indiretamente por meio da reconstrução das experiências de injustiça. Como afirma Honneth, "a moralidade interna da consciência de injustiça social pode ser compreendida apenas indiretamente, na base de critérios colocados pela desaprovação moral dos eventos e processos sociais" (idem, ibidem). Para identificá-la, é preciso olhar para os elementos negativos e confusos das experiências de injustiça e reconstruir, de modo indireto, as expectativas positivas de justiça que estão contidas nelas.

Essa reconstrução negativa depende, segundo Honneth, de um processo duplo de abstração. Em primeiro lugar, é preciso abstrair dos casos em que esses sentimentos já foram sistematizados, seja por vanguardas políticas, seja pelos próprios concernidos. ${ }^{12}$ Além disso, é preciso abstrair dos diversos mecanismos estatais

11 Honneth está pensando aqui nas classes trabalhadoras. Seyla Benhabib e Carol Gilligan desenvolvem uma crítica semelhante ao argumento de Kohlberg, a partir de uma perspectiva de gênero, explicitando que o modelo de Kohlberg tende a estigmatizar outros grupos, como o de mulheres, além de ignorar a ampliação do ponto de vista moral que poderia advir da inclusão do ponto de vista do outro concreto no interior do juízo moral (Benhabib 1992; Gilligan 1982).

12 As pesquisas empíricas mostram, para Honneth, que os trabalhadores conseguem articular de modo mais maduro e normativamente seguro questões que dizem respeito ao seu entorno do que questões mais gerais sobre a ordem social, nas quais recaem em sensos comuns (Honneth 1981, pp. 211-2; Teixeira 2016, pp. 101-3). 
e institucionais que bloqueiam a articulação e a publicização desses sentimentos de injustiça. Mecanismos dos quais fazem parte a exclusão cultural, que prejudica as capacidades simbólicas dos indivíduos e impede que eles articulem seus sentimentos de injustiça, e a individualização institucional, que promove atitudes individualistas e corrói a infraestrutura comunicativa da qual depende a elaboração cooperativa das experiências de injustiça. Ao defender esses dois pontos, Honneth reforça que as experiências brutas de injustiça são o ponto de partida mais adequado para seu projeto reconstrutivo, mesmo que elas também sejam afetadas por mecanismos de dominação. É nesse sentido que ele afirma que, embora seu projeto dependa de uma compreensão dos mecanismos de dominação e de seus efeitos, ele também requer uma abstração deles, para que se possa encontrar "as indicações inarticuladas de condenação moral da atual ordem social", indicações que estariam "ocultas nas lutas amplamente individualizadas por reconhecimento social e nas lutas cotidianas nos espaços de trabalho" (idem, p. 199 [p. 218]).

Um dos potenciais de conflito encontrados por Honneth nesse período está, então, atrelado à distribuição das chances de reconhecimento social e possui um caráter fortemente intersubjetivo. Segundo ele, em uma sociedade na qual o reconhecimento social desfrutado por indivíduos e grupos sociais depende do grau de estima atribuído às diferentes profissões e ocupações, mas as chances de acesso a elas são desigualmente distribuídas, uma parcela significativa da população é privada das experiências de reconhecimento intersubjetivo das quais a formação bem-sucedida de sua identidade depende. Como afirma Honneth, a partir do estudo de Sennett e Cobb (1973), essa privação não é experienciada com indiferença pelos indivíduos, que reagem a ela buscando obter uma forma de respeito contracultural compensatório. Essas tentativas envolvem tanto estratégias para aumentar a valorização de determinadas funções socialmente menosprezadas, como estratégias para ridicularizar funções melhor remuneradas e reconhecidas. Nos dois casos, são formas de buscar estima social dentro de uma ordem hierárquica de reconhecimento. 0 segundo potencial de conflito discutido por Honneth nesse artigo retoma as estratégias de reapropriação do trabalho já discutidas no texto de 1980. Como afirma ele, as mudanças na esfera da produção daquele período tiraram, sobretudo dos trabalhadores de classes mais baixas, a possibilidade de se reconhecerem e autorrealizarem em seus trabalhos, que se tornaram monótonos e independentes de qualquer iniciativa individual. Essa expropriação, todavia, é sentida pelos concernidos como injusta e dá origem a reações morais, que podem ser observadas em suas diversas estratégias para recobrar o controle sobre a atividade produtiva.

Mesmo que latentes, essas duas formas de conflito mostram, segundo Honneth, que os sujeitos sociais possuem a expectativa moral de serem reconhecidos e a de controlarem autonomamente seus trabalhos. Essas expectativas, por sua 
vez, explicitam potenciais de transformação social. Isso porque a violação dessas expectativas morais é experienciada pelos sujeitos sociais com indignação e pode motivar lutas por reconhecimento social e por uma organização autônoma do trabalho. Tendo isso em vista, Honneth esboça o projeto de desenvolver uma fenomenologia do sentimento de injustiça que parte da análise de conflitos latentes e cotidianos. Lançando mão dessa estratégia, ele acredita poder articular, numa mesma teoria, o sofrimento gerado pelas relações alienadas de trabalho e pelas distorções na interação social, ao mesmo tempo em que aponta para a possibilidade real de sua superação prática. Ele conseguiria, nesse sentido, rearticular as contribuições de Marx e Habermas em uma teoria crítica que não incorre nos mesmos problemas de suas teorias, na medida em que mostra que os conflitos sociais são desencadeados pela frustração das expectativas sociais dos sujeitos e possuem um caráter moral. Para poder realizar esse projeto, contudo, Honneth tem primeiro que mostrar, mais claramente, como essas diferentes experiências de ofensa moral se originam e no que elas estão baseadas. ${ }^{13}$ Tendo isso em vista, ele se volta à análise da experiência de injustiça e começa a reconstruir as bases daquela que virá a ser sua teoria social crítica do reconhecimento.

\section{Justificação moral e experiências de injustiça: das mediações necessárias}

No decorrer da década de 1980, Honneth se dá conta da dificuldade de estabelecer um vínculo entre a formação das expectativas morais dos sujeitos, sua violação e a motivação das lutas sociais, e reconhece que subestimou, nesse primeiro momento, "o número de mediações necessárias para forjar uma conexão entre o nível de justificação de normas morais e a análise empírica das motivações morais" (Honneth 1995, p. xiv). ${ }^{14}$ Afirmando que o material coletado até então

$13 \mathrm{Em}$ um artigo dedicado à discussão do livro de Barrigton Moore Injustiça (1978), Honneth procura compreender, por um lado, o que leva os indivíduos a aceitarem ordens sociais que são desvantajosas e, por outro lado, o que os motiva lutar por sua transformação. Aproximando-se de Moore, Honneth parece ressaltar, nesse texto, a importância de acordos morais frágeis e não-verbalizados, que são continuamente renovados por meio das ações dos indivíduos, para a manutenção da crença na legitimidade na ordem social (Honneth 1984). Segundo ele, é a violação a esses consensos tácitos aquilo que os indivíduos experienciam como injusto e que pode desencadear conflitos sociais (Piromalli 2012b). Ao se aproximar dessa concepção, como mostra Teixeira, Honneth se afasta de sua posição anterior, de acordo com a qual o fato de que as pessoas continuam desempenhando pragmaticamente suas funções em processos de reprodução social não significa que eles a considerem como legítima (Teixeira 2016, p. 107). A nosso ver, essa mudança é importante para a compreensão de determinados aspectos da teoria do reconhecimento desenvolvida por Honneth, em particular sua dificuldade de dar conta da negatividade social (Bressiani 2016). Esse ponto, contudo, extrapola o escopo do presente artigo.

$14 \mathrm{Em}$ um livro no qual apresenta alguns comentários e estudos preparatórios para a teoria da ação comunicativa, publicado em 1980, Habermas critica, nesses termos, o projeto honnethiano de resgatar o potencial normativo do trabalho a partir de uma reconstrução das práticas de contestação ainda existentes (Habermas 1980, p. 484). Embora o texto não seja citado nesse momento, Honneth 
mostra que é "principalmente a violência contra demandas individuais ou coletivas de reconhecimento social no mundo da vida que é experienciada como injustiça moral”, Honneth estabelece a gramática moral das relações de reconhecimento como o ponto de referência normativo de sua teoria (idem, p. xv). Lançando mão de uma estratégia negativa de reconstrução, que toma as experiências de desrespeito como ponto de partida, Honneth procura mostrar que a formação da identidade do indivíduo depende de relações de reconhecimento, por meio das quais os sujeitos formam as expectativas morais de comportamento que dirigem aos seus parceiros de interação. Com base nisso, ele passa a sustentar que é a violação de pretensões de identidade, causada pela negação do reconhecimento, que gera no sujeito uma experiência de desrespeito que pode desencadear lutas morais por reconhecimento.

Honneth busca, com isso, estabelecer as mediações que faltavam à sua teoria. Ao dar centralidade à reconstrução das dinâmicas normativas da interação social, no entanto, ele parece abrir mão exatamente de uma das suas principais teses até então: a de que não se pode, como Habermas, ignorar o potencial crítico inscrito na atividade do trabalho. ${ }^{15}$ Embora continue defendendo que o capitalismo pode ser criticado a partir de dentro, Honneth afirma agora que essa crítica não tem como partir de uma normatividade inerente à atividade do trabalho, mas somente das condições necessárias para a formação intacta da identidade, dentre as quais figura o reconhecimento social pelas contribuições realizadas por meio do trabalho. Segundo Honneth, "as regras que regulam a organização do trabalho têm de ser compreendidas segundo o quadro mais geral das regras de interação", por isso "os critérios que estão na base de sua avaliação têm de ser os mesmos que se aplicam à justificação de normas em geral" (idem, p. xviii). Assim, se, em um primeiro momento, ele tentou reformular um conceito crítico de trabalho para se contrapor à interpretação que Habermas faz dessa atividade, agora ele compreende a normatividade do trabalho a partir da interação. Seu foco se volta, com isso, às relações de cooperação entre os trabalhadores e à dependência que os indivíduos têm de serem reconhecidos por suas contribuições à reprodução da sociedade. As relações de trabalho e a distribuição desigual de renda passam a ser questionadas na medida em que constituem uma relação danificada de reconhecimento social (Petherbridge 2013, pp. 22-3).

Honneth passa a compreender as patologias sociais como o resultado de

reconhece posteriormente sua importância e admite ter aceitado a objeção. Como afirma Honneth em "Trabalho e Reconhecimento", de 2008, "Jürgen Habermas objetou afirmando que [...] eu sucumbira a um 'sofisma genético' porque da pura existência de determinados desejos e exigências deduzia sua justificabilidade moral: não as presuntivas exigências dos atingidos, mas apenas discursos práticos poderiam fundamentar moralmente decisões sobre quais as normas que deveriam prevalecer numa dada organização do trabalho" (Honneth 2008, p. 52).

15 Corroborando essa hipótese, Honneth reconhece, na introdução da edição americana de Fragmentado mundo do social, que "pode-se objetar hoje com razão que os critérios para a avaliação moral não estão relacionados com o caráter interno do próprio processo de trabalho, e sim com o quadro institucional no qual ele está necessariamente ancorado" (Honneth 1995, p. xviii). 
distorções nas relações recíprocas de reconhecimento, das quais depende a formação da identidade do sujeito. Com essa mudança, ele se aproxima de Habermas. Assim como este, Honneth extrai o critério de sua teoria da inviolabilidade da interação social, que reconstrói nos termos de relações de reconhecimento e não como ações comunicativas. Vale ressaltar, contudo, que essa aproximação não deve ser interpretada como um recuo de Honneth no que se refere à tese de que é possível realizar uma crítica imanente da organização social do trabalho no capitalismo. Ainda que em um nível mais abstrato e sobre bases intersubjetivas, o objetivo de Honneth continua sendo dar conta do projeto marxista, tal como ele o compreende. Como diz Honneth:

a convicção de que um ser humano só pode alcançar uma identidade satisfatória por meio da experiência integral das conquistas de seu próprio trabalho é uma premissa básica implícita no conceito marxista de trabalho (...) Marx não concebe a luta de classes apenas como um conflito estratégico acerca da aquisição de bens ou de poderes de comando; pelo contrário, ela representa um tipo de conflito moral em que a classe oprimida está lutando para obter as condições sociais para seu autorrespeito... a interpretação histórico-filosófica que fornece o quadro geral no interior do qual a análise marxista da sociedade capitalista de classes está ancorada incorpora uma perspectiva que deriva da lógica do reconhecimento e não da do trabalho: sob as condições econômicas do capitalismo, o processo de reconhecimento mútuo entre seres humanos é interrompido porque um grupo social não possui precisamente aquelas precondições necessárias para a obtenção do respeito (Honneth 1989a, pp. 103-5 [1995, pp. 12-3]).

Em um nível mais abstrato, a tese central de Marx seria exatamente a de que os seres humanos só conseguem desenvolver suas identidades de modo satisfatório se forem socialmente reconhecidos pelo seu trabalho. Assim, formas de organização do trabalho como a capitalista, que impedem esse reconhecimento intersubjetivo, ferem os sujeitos em sua dignidade e em seu autorrespeito.

Para Honneth, portanto, as lutas pela transformação do trabalho e por melhores salários não devem ser entendidas como um conflito estratégico. O motor das lutas de classe não decorre simplesmente da miséria gerada pelo capitalismo, mas do fato de que este destrói as condições sociais para a formação bem-sucedida da identidade. Ao desenvolver sua teoria do reconhecimento, Honneth não abandona, mas reformula a noção de luta de classes. Além disso, ele também não abandona, mas reformula o projeto de desenvolver uma crítica imanente da economia capitalista enquanto uma relação danificada de reconhecimento social. Nesse sentido, não procede a acusação de que Honneth, ao dar centralidade ao conceito de reconhecimento, teria simplesmente desconsiderado questões e injustiças relacionadas à economia capitalista (Fraser 2001). Entretanto, caberia ainda analisar se a teoria do reconhecimento, desenvolvida ao longo da década seguinte, dá conta dessa tarefa. Para isso, para continuar com Fraser, seria ainda preciso analisar se o monismo moral desenvolvido por Honneth não pressupõe um monismo de caráter teórico-social e, além disso, até que ponto 
as abstrações exigidas pelo método negativo de reconstrução, desenvolvido por Honneth nesse período, não acabam por fazê-lo perder de vista o caráter ambíguo das experiências de injustiça (Fraser 2003a, 2003b; Bressiani 2011, 2016).

\section{Referências}

Arendt, H. (2005). Entre o passado e o futuro. São Paulo: Editora Perspectiva. Arendt, H. (2007). A condição humana. São Paulo: Ed. Forense Universitária.

Benhabib, S. (1992). Situating the self. Gender, community and postmodernism in contemporary ethics. New York: Routledge.

Bernoux, P. (1979). La résistance ouvrière à la rationalisation: la réappropriation du travail. Sociologie du Travail, 21(1), 76-90.

Braverman, H. (1978). Trabalho e Capital Monopolista: a Degradação do Trabalho no Século XX. São Paulo; LTC; Edição: 3.

Bressiani, N. (2011). Redistribuição e Reconhecimento. Nancy Fraser entre Jürgen Habermas e Axel Honneth. Cadernos CRH, 24(62), 331-352. DOI: https: //doi.org/10.1590/S0103-49792011000200007

Bressiani, N. (2016) Monismo social ou moral? Dos pressupostos teórico-sociais da teoria do reconhecimento de Axel Honneth. Ethic@ (UFSC), 15(1), 169-190. DOI: https://doi.org/10.5007/1677-2954.2016v15n1p169

Deranty, J.-P. (2009). Beyond Communication. A critical study of Axel Honneth's Social Philosophy. Leiden; Boston: Brill.

Fraser, N. (2001). "Da Redistribuição ao Reconhecimento? Dilemas da Justiça na Era Pós-Socialista". In Souza, J. Democracia Hoje. Novos Desafios para a Teoria Democrática Contemporânea (pp. 245-282). Brasília: UNB.

Fraser, N. (2003a). “Distorted Beyond All Recognition: A Rejoinder to Axel Honneth”. In Fraser, N. \& Honneth, A. Redistribution or Recognition? A political-philosophical exchange (pp. 198-236). New York: Verso.

Fraser, N. (2003b). "Social Justice in the Age of Identity Politics: Redistribution, Recognition and Participation". In Fraser, N. \& Honneth, A. Redistribution or Recognition? A political-philosophical exchange (pp. 7-109). New York: Verso.

Gehlen, A. (2016). Der Mensch. Seine Natur und seine Stellung in der Welt. Frankfurt am Main; Klostermann, Vittorio.

Gilligan, C. (1982). In a different voice. Psychological theory and women's development. Cambridge MA: Harvard University Press.

Habermas, J. (1976). Zur Rekonstruktion des Historischen Materialismus. Frankfurt am Main: Suhrkamp.

Habermas, J. (1980) Replik auf Einwände. In Habermas, J. Vorstudien und Ergänzungen zur Theorie des kommunikativen Handelns (p. 475-570). Frankfurt am Main: Suhrkamp.

Habermas, J. (2011). Técnica e Ciência como “Ideologia”. São Paulo: UNESP. 
Honneth, A. (1980). „Arbeit und instrumentales Handeln. Kategoriale Probleme einer Kritischen Gesellschatstheorie“. In Honneth, A. \& Jaeggi, U. Arbeit, Handlung, Normativität. Theorien des Historischen Materialismus 2 (pp. 185-233). Frankfurt am Main: Suhrkamp. [Work and instrumental action: on the normative basis of critical theory. In Honneth, A. (1995) Fragmented world of the social. Essays in social and political philosophy (pp. 15-49). New York: State University of New York Press].

Honneth, A. (1981). Moralbewusstsein und soziale Klassenherrschaft. Einige Schwierigkeiten in der Analyse normativer Handlungspotentiale. Leviathan, 9 (34). [Moral Consciousness and Class Domination: Some problems in the Analysis of hidden morality. In Honneth, A. (1995) The fragmented world of the social. Essays in social and political philosophy (pp. 3-14). New York: State University of New York Press].

Honneth, A. (1982). "Von Adorno zu Habermas. Zum Gestaltwandel kritischer Gesellschaftstheorie“. In Honneth, A. \& Jaeggi, U. (Eds) Sozialforschung als Kritik. Zum sozialwissenschaftlich Potential der kritischen Theorie. Frankfurt am Main: Suhrkamp. [From Adorno to Habermas. On the transformation of critical social theory. In Honneth, A. (1995) Fragmented world of the social. Essays in social and political philosophy (pp. 92-120). New York: State University of New York Press].

Honneth, A. (1984) Moralischer Konsens und Unrechtempfindung. Zur Barrignton Moore Untersuchung 'Ungerechtigkeit'. Suhrkamp Verlag Wisseschaft. Weißes Programm. Almanach. (pp. 108-144). Frankfurt am Main: Suhrkamp.

Honneth, A. (1987). “Critical Theory”. In Giddens, A. \& Turner, J. Social Theory Today. Stanford CA: Stanford University. [Honneth, A. (1996). Teoria Crítica. In Giddens, A. \& Turner, J. Teoria social hoje (pp. 503-552). São Paulo: UNESP].

Honneth, A. (1989a). „Zur Logik der Emanzipation. Zum philosophischen Erbe des Marxismus“. In Honneth, A. \& Bonß, W. (Eds). Wege ins Reich der Freiheit. Berlin: Rotbuch, 1989. [Domination and Moral Struggle: the philosophical heritage of Marxism reviewed. In Honneth, A. (1995) The fragmented world of the social. Essays in social and political philosophy (pp. 3-14). New York: State University of New York Press].

Honneth, A. (1989b). Kritik der Macht. Reflexionsstufe einer kritischen Gesellschaftstheorie. Frankfurt am Main: Suhrkamp.

Honneth, A. (1992). Kampf um Anerkennung. Zur Moralischen Grammatik sozialer Konflikte. Frankfurt am Main: Suhrkamp. [Honneth, A. 2003. Luta por reconhecimento. A gramática moral dos conflitos sociais. São Paulo: Editora 34].

Honneth, A. (1995). “Introduction". In Honneth, A. The fragmented world of the social. Essays in social and political philosophy (pp. xi-xxv). New York: State University of New York Press.

Honneth, A. (2008). Trabalho e reconhecimento: tentativa de uma redefinição. Civitas - Revista De Ciências Sociais, 8(1), 46-67. DOI: https: / /doi.org/10.15448/1984-7289.2008.1.4321

Honneth, A., \& Jaeggi, U. (1980). Arbeit, Handlung, Normativität. Theorien des Historischen Materialismus 2. Frankfurt am Main: Suhrkamp. 
Honneth, A., \& Joas, H. (1980). Soziales Handeln und menschliche Natur. Antropologische Grundlagen der Sozialwissenschaften. Frankfurt am Main: Campus Verlag.

Melo, R. (2013a). Marx e Habermas. Teoria crítica e os sentidos da emancipação. São Paulo: Saraiva.

Melo, R. (2013). "Práxis social, trabalho e reconhecimento". In Melo, R. A teoria crítica de Axel Honneth. Reconhecimento, liberdade e justiça (pp. 145-180). São Paulo: Saraiva.

Moore, B. (1987). Injustiça: as bases sociais da obediência e da revolta. São Paulo: Brasiliense.

Petherbridge, D. (2013). The critical theory of Axel Honneth. Plymouth: Lexington Books.

Piromalli, E. (2012a). Axel Honneth. Giustizia Sociale come Riconoscimento. Milano: Mimesis.

Piromalli, E. (2012b). Marxism and Cultural Studies in the Development of Axel Honneth's Theory of Recognition. Culture, Theory and Critique, 53(3), 249-263. DOI: https://doi.org/10.1080/14735784.2012.720439

Sennett, R. \& Cobb, J. (1973). The hidden injuries of class. New York: Knopf.

Teixeira, M. (2016). Patologias sociais, sofrimento e resistência. Reconstrução da negatividade latente na teoria crítica de Axel Honneth. Tese de Doutorado. Instituto de Filosofia e Ciências Humanas da UNICAMP, 405p.

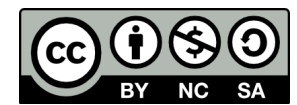

